\title{
Scientists suggest insertion of nanoscience and technology into middle school physics
}

\author{
Ella Yonai®* and Ron Blonder® $\oplus^{\dagger}$ \\ Department of Science Teaching, Weizmann Institute of Science, Rehovot 76100, Israel
}

(Received 18 July 2019; accepted 6 January 2020; published 10 March 2020)

\begin{abstract}
The goal of this research is to provide a rich set of connections between two fields: (i) Nanoscale science and technology (NST) and (ii) topics from a common middle school physics curriculum. NST is emerging as one of the most promising new fields of the 21st century, which is one of the many arguments for including NST topics in secondary science education. A specially designed guided discourse with NST scientists was used to produce a map of connections between the two fields. During the discourse, the scientists were presented with two sets of concepts using a visual board and were asked to find connections between them. All suggested connections and the corresponding context offered by the scientists were arranged and presented as a rich set of connections. For example, (i) the NST concept of characterization methods is connected to mechanical forces and can be explained using the example of an atomic force microscope; (ii) the NST concept of size-dependent properties was connected to 7th grade inquiry skills by explaining the size dependence of accuracy, errors, and defects. This set of connections was validated by an experienced middle school science teacher in an open discussion regarding teachers adopting and implementing the resulting insertion points for the curriculum. This resulting set of connections can be used to enrich the curriculum within the NST field. It also provides a perspective on scientists' views regarding insertion of contemporary NST topics into physics middle school education.
\end{abstract}

DOI: 10.1103/PhysRevPhysEducRes.16.010110

\section{INTRODUCTION}

In the last decade, there has been a growing attempt to introduce topics of modern science and technology into secondary school science education [1]. Nanoscale science is considered a good candidate as a contemporary topic to be integrated into school science teaching. This is due to its interdisciplinary nature and relevance to many curricular topics [2]. Nanoscale science and technology is relevant to all natural and living systems that are governed by atomic and molecular behavior at the nanoscale [3].

The insertion of concepts, applications, and ideas of contemporary science into a traditional secondary science curriculum is a process that requires a deep understanding of both fields. This research is based on work done by Sakhnini and Blonder, who conducted a Delphi study to identify the essential concepts of nanoscale science and technology (NST) for secondary education [4]. The study involved participants from two different groups: (i) scientists who are considered experts in the field of NST and (ii) experienced educators from different scientific disciplines. Using the

\footnotetext{
*Ella.yonai@weizmann.ac.il

†Ron.Blonder@weizmann.ac.il
}

Published by the American Physical Society under the terms of the Creative Commons Attribution 4.0 International license. Further distribution of this work must maintain attribution to the author(s) and the published article's title, journal citation, and DOI.
Delphi study methodology [5], the groups reached a consensus on 7 NST essential concepts that are recommended to be taught in secondary school science. The list of the essential concepts is presented in Table I.

NST is an interdisciplinary field combining content knowledge from chemistry, biology, physics, materials science, medicine, and engineering [7]. This work focuses on integrating NST with physics into secondary education, which has proven to be a challenging task. In a previous attempt [8], 11 middle and high-school science teachers were asked to identify insertion points for NST essential concepts in the middle school general science curriculum, which consisted of 4 main disciplines: chemistry, physics (energy), life sciences, technology systems, and products

TABLE I. Seven essential concepts of NST for secondary education found in the Delphi study [4]. An 8th concept identified in this study is related to the nature of the NST field [6] and is not a scientific concept and was therefore removed from the list.

7 Essential Concepts of Nanoscale Science and Technology

1. Size-dependent properties

2. Innovations and applications of NST

3. Size and scale

4. Characterization methods

5. Functionality

6. Classification of nanomaterials

7. Fabrication approaches 
(engineering). In Israel, often a single teacher teaches all these different subjects in middle school. It is common to find that these teachers have an academic degree in biology, since teachers with a degree in chemistry and physics are rarer at this level. The teachers that participated in this study taught all of these topics in middle school, had a degree in biology or chemistry, and had completed a course designed by the researcher on the essential NST concepts. The results indicated that only two of the NST essential concepts were inserted into the physics topics. Namely, the teachers were unable to find connections between the remaining NST essential concepts and the physics part of the curriculum. The teachers found the Chemistry part of the curriculum to be more naturally connected to the NST essential concepts. This finding was explained by the fact that the teachers, though experienced in teaching the middle school multidisciplinary science curriculum, did not have a solid background in physics. Teaching physics, like any scientific field, requires a strong content knowledge and academic expertise [9]. This expertise may be essential for finding connections between the physics curriculum and the NST concepts. The physics curriculum is characterized as hierarchical in nature [10], whereby the curriculum emphasizes basic physics of the distant past. In all secondary physics curricula surveyed for this work, NST was not formally presented to students at any stage of their education. Students will first encounter this subject only when they reach advanced undergraduate courses in academic studies.

If we wish to introduce contemporary physics to our students using the NST context in secondary education, we need to find suitable content and insert it into the secondary physics curriculum. There is a need for additional research in order to find connections between the physics school curriculum and the NST framework of essential concepts. For educators and curriculum designers, NST provides a rich context to introduce modern topics into the curriculum in relation to secondary school physics.

\section{RESEARCH QUESTION}

The main goal of this part of the research is to build a research-based, rational map of connections between essential NST concepts and a common middle school physics curriculum in Israel: "The scientific technological provision program" [11]. Although this research refers to a certain middle school physics curriculum termed "the scientific technological provision program," the topics included can be found in other standard middle school physics programs in Israel and around the world. We applied a positivistic paradigm in this work, which is centered on the criteria of two fixed items: the physics middle school curriculum and the NST essential concepts. This perspective was designed in order to address two questions regarding the experts' approach and views regarding inserting NST into middle school physics education. These questions deal with curricular structure and specific NST-related examples that may be used in the classroom, according to physics experts in NST:

1. What are the suggested insertion points for NST concepts in a middle school physics curriculum?

2. How can we present NST concepts, examples, and contemporary research and integrate them into the context of a middle school physics curriculum?

\section{METHODS}

We seek to identify the possible connections between school science topics and contemporary science topics. Our goal is to present this knowledge as a map of insertion points of contemporary science topics, insert these points into curricular topics, and provide examples of their context for these insertions.

\section{A. Participants}

Following previous work in our group on this topic $[8,12]$, as described in the Sec. I, we chose to isolate the example of a physics middle school curriculum and the contemporary field of NST essential concepts. We interviewed experts from the physics scientific community and asked them to suggest points where NST could be inserted into the physics curriculum. All participants had academic degrees in physics or engineering field strongly related to physics (e.g., mechanical engineering). These 12 academic professionals (who are considered experts in physics) conduct (their recent research or have in the past) research in the NST field, which is strongly connected to physics. Each of the scientists has a unique arsenal of explanations and examples that can be used to create an integrative set of insertion points of NST essential concepts for insertion into the physics middle school curriculum. Their suggestions were gathered and analyzed to construct a map of insertion points.

The tool for collecting data is a structured exercise led by the researcher (E. Y.) [13]. She also has had experience as a physics teacher in middle school and high school in several schools in Israel. The experts were presented with the essential NST concepts and the main topics of the middle school physics curriculum and were asked to provide points where NST can be inserted into a traditional set of physics topics. They were also asked to provide the rationale behind making each of the individual connections. This process took about $1 \mathrm{~h}$ for each expert.

\section{B. Research tool: The interview board}

To connect the two fields, the participants should keep in mind a lot of specific information that they may not originally possess. This need influenced the design of the data collection process. The participants are experts in the field of NST and physics but probably are not familiar with the essential concepts of NST identified in a recent study [4] nor with the details of the physics secondary 
school curriculum. We therefore designed an interview board that will help them keep in mind the NST essential concepts and the structure of the middle school physics curriculum.

The interview was conducted as a discourse between the researcher and the physics expert. It started by giving the participants (physics experts) information in order to frame the relevant physics context for the insertion process. The information included a general view of the middle school physics curriculum, from the interviewer's perspective as a teacher, in each of the grades, with emphasis on teaching goals and key concepts. For assistance, in presenting all this information and keeping it in mind during the discourse, a visual representation board of the information was used (Fig. 1). The information on the board appeared in the form of a cognitive map [14] that preserves all the details of the map as a context for the discourse.

After the curricular information is presented, each NST essential concept is orally presented and an ID card with research-based definitions and common examples (Appendix A) is given to the researcher. These cards are placed at the top of the board to remind the participant the NST concept that is discussed (see Fig. 1). After presenting an ID card, the participant is requested to insert icons representing a certain concept into the physics middle school curriculum. Next, the participant is asked to place the icons of the NST concept near a curricular topic to represent a connection. The participant is then asked to explain the connection and to provide examples that demonstrate the connection. Establishing the "explanatory story" behind each connection will be useful for constructing future explanations and examples [9]. Thus, the board served as a tool to document all the indicated connections and provided an overall picture of the participants' point of view, as presented in Fig. 2. This process of presenting ID cards and making connections was repeated for each the seven essential concepts. After discussing and making connections for all seven essential concepts with the physics curriculum, the interview board was documented by a photograph, as presented in Fig. 2 .

Note that the interviewer's knowledge and experience as a physics middle school teacher came into play during the discourse. The scientists often asked for clarifications and examples of how the presented physics topics were taught in class. They also often asked about equipment and laboratory work in school science. The interviewer took extra care not to express an opinion regarding the suggested insertion points and only shared additional information regarding topics that the scientists inquired about.

\section{Validation stage: Teachers' interviews}

In order to validate the suggested insertion point made by the physics experts, the analyzed results of the interviews with the physics experts were examined by an experienced middle school teacher. After carrying out the set of

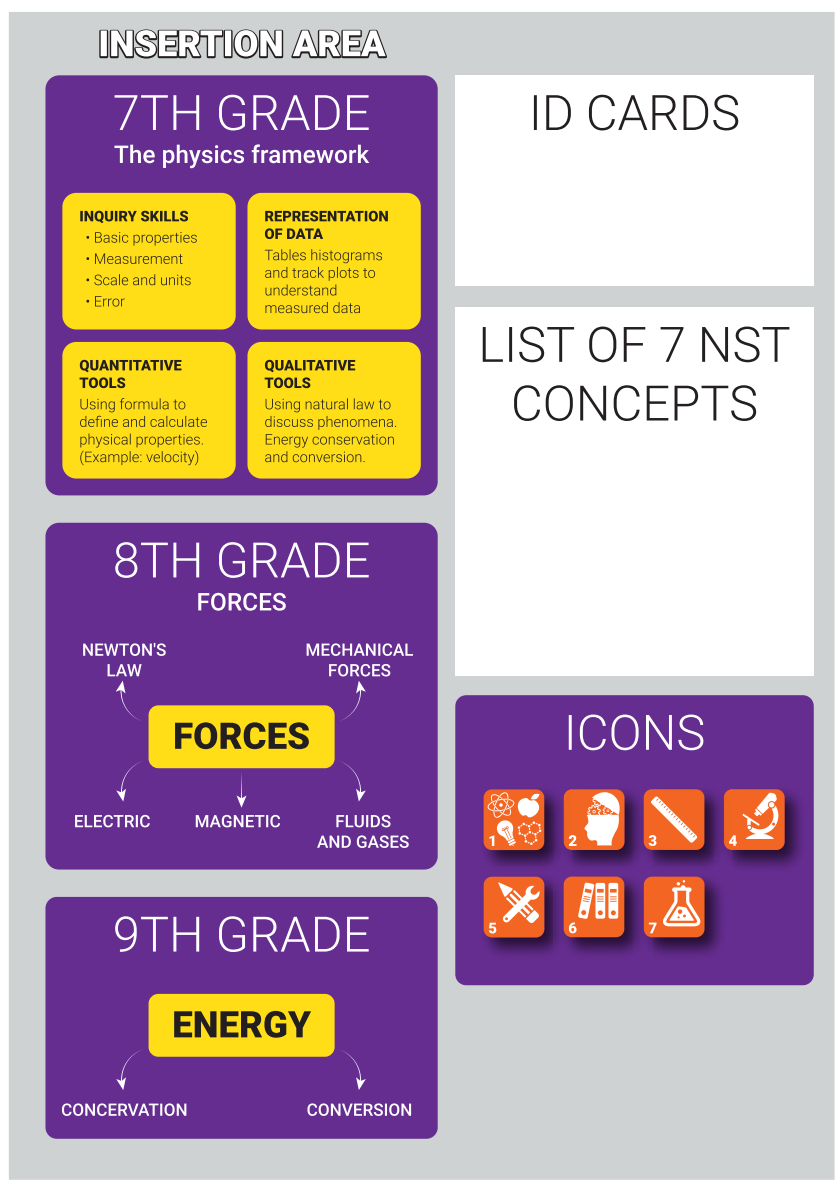

FIG. 1. A schematic of the designed discourse board. In the white area of the board, the interviewer placed the NST concept cards during the discourse; the cards contain information about the NST concepts.

12 interviews and summarizing the results in tables by topics and concepts, another discourse was set up with a middle school science teacher. The purpose of this discourse was to view the insertion points from the perspective of a practicing middle school teacher, thus validating the results. The teacher selected for this purpose was an active middle school teacher who teaches according to the science curriculum including the physics topics. She has a BSc degree in chemistry (and represents many middle school science teachers that teach physics without having a degree in physics). However, she has an extended knowledge of NST and she was involved in conducting the study for finding insertion points by middle school teachers [8]. This background provided her with a broad perspective on the challenges of inserting NST into the science curriculum. The discourse was conducted by the same researcher as a discussion between teachers on the scientists' insertion points, raising possible challenges and concerns regarding specific topics and insertions.

In the first part of the discourse with the teacher, she was introduced to the process that the scientists underwent before they provided the insertion points (as described 


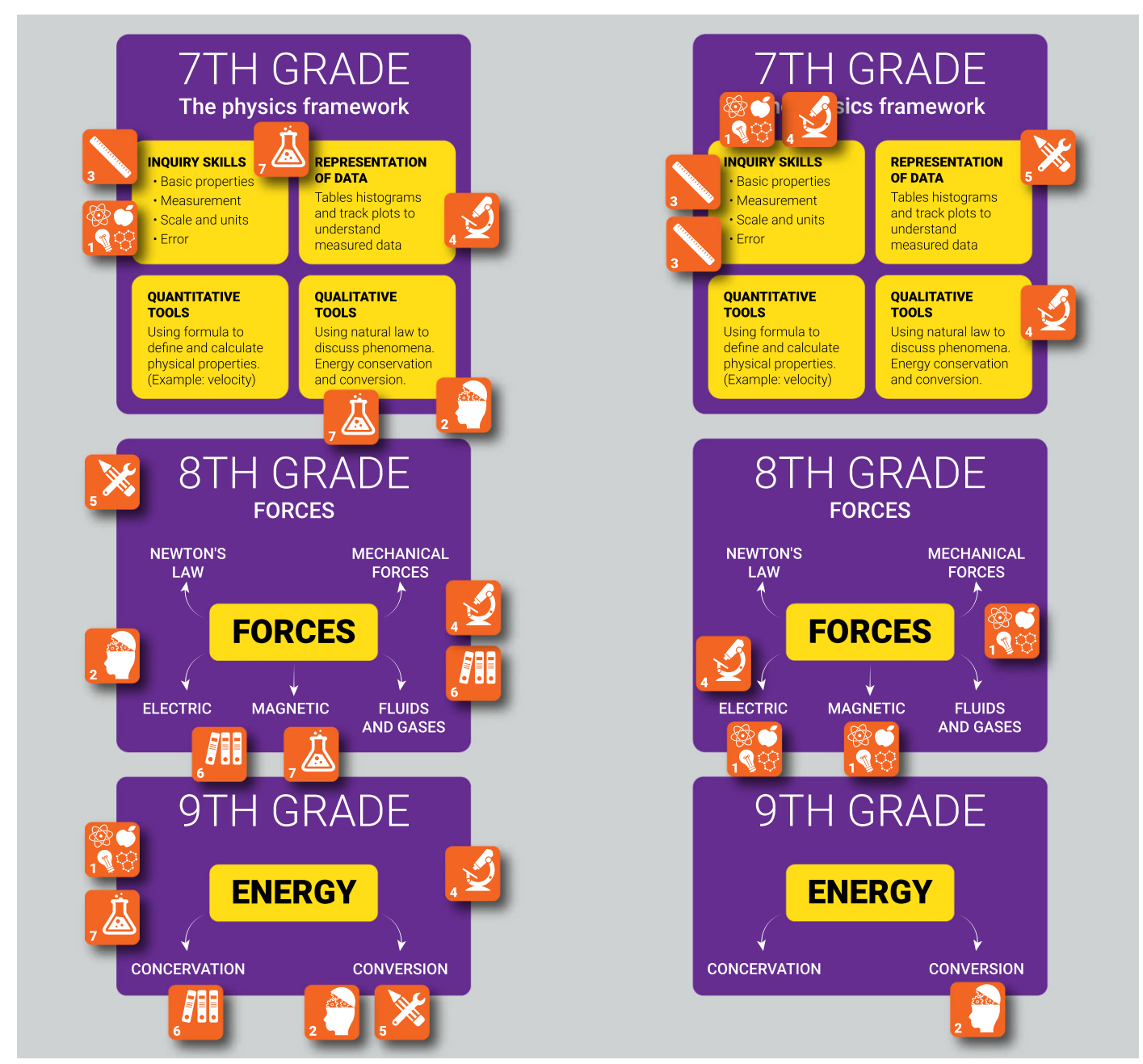

FIG. 2. The interview board at the end of the exercise. Boards of two different experts for each icon signify a connection made and explained by the expert, presenting an overall picture of one participant's point of view.

above regarding the interview board). In the next part, she was presented with the tables of summarized insertion points (presented in the results and Appendix B) and was asked to examine the results and mark examples that she does not agree with or has comments about. The last part of the discourse was an open discussion about the insertion points and the items raised for discussion.

\section{Data analysis}

All discourses were transcribed and explanatory stories were extracted according to the map of connections recorded for every individual discourse. The insertion points that were collected in each discourse were sorted by grades, curricular topics, and NST concepts to obtain different points of view regarding the data. At the beginning of the data collection process, namely, the conduction of interviews, every discourse added new insertion points with different explanations. This collection process eventually reached a level of saturation when the new connections added by each discourse were $5 \%-10 \%$ of all the connections given in the discourse. Reaching this point indicated to the researchers that the set of insertion points had been completed, thus allowing the data collecting process to end.

\section{RESULTS}

In this part we present the results of collected insertion points from the 12 interviews conducted with NST scientists in the framework of the middle school physics curriculum. The data were very rich in nature and could be presented and represented in various ways. The way data are presented here was selected not because of esthetics but rather to convey our systematic approach for connecting these two fields: the physics middle school curriculum and essential NST concepts. This approach will dictate how we present these results and it will be further described in Sec. V.

\section{A. The NST education point of view}

First, we present all the suggested insertion points ( $N=130)$ of NST concepts according to the curricular 
30

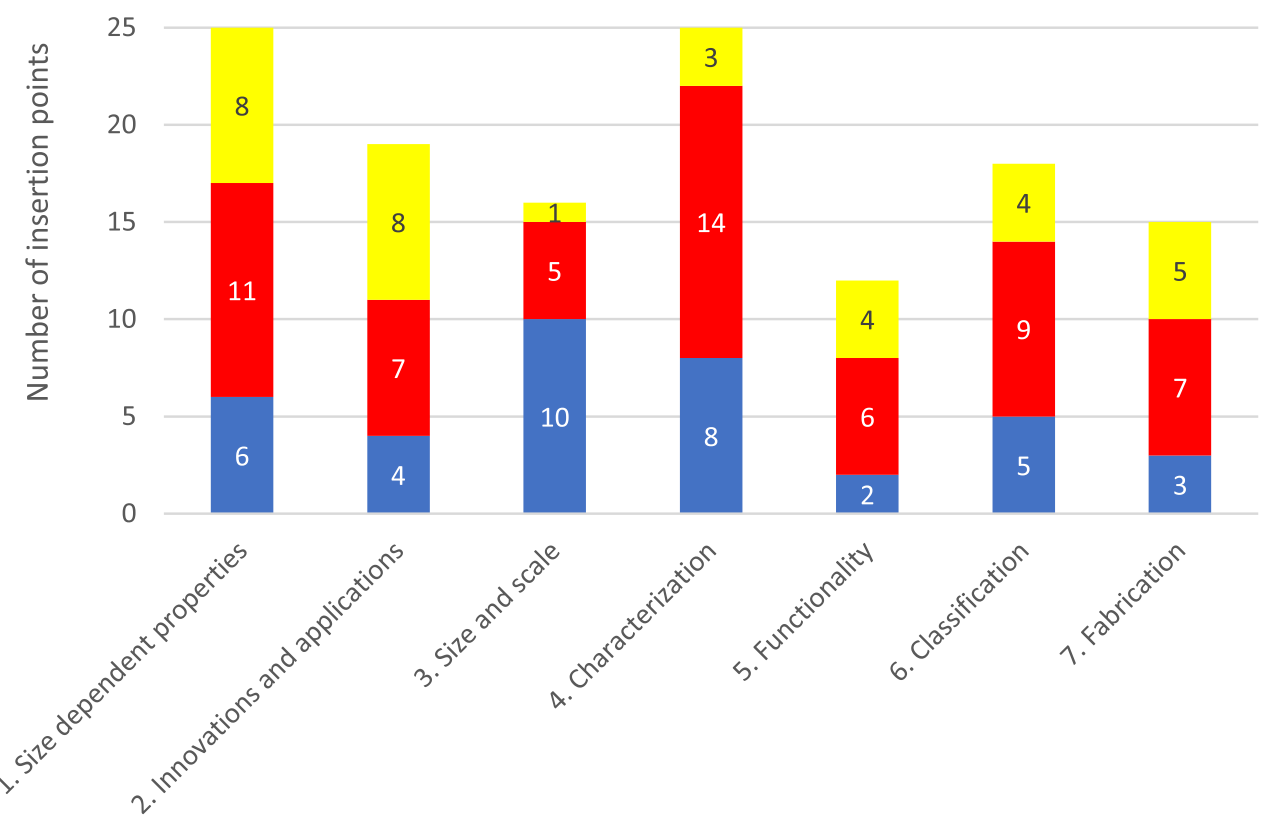

NST concept

-7th Grade $\quad$ 8th Grade $\quad$ 9th Grade

FIG. 3. The sum of insertion points for each NST concept in the middle school physics curriculum according to grade (obtained from 12 participants).

topics in different grades (levels, Fig. 3). The research methodology allowed us to obtain these data easily using the photos taken at the end of each interview board by counting the icons that represent each concept. These results were validated by systematically examining the audio recordings of the interviews, which led to altering about $5 \%$ of the data, mostly because of icons that were put in an unsuitable or unclear place.

As seen in Fig. 3, all concepts are represented in every grade. The most frequently mentioned concepts were the first concept, size-dependent properties, and the 4th NST concept, characterization methods. The 5th concept, functionality, is the least connected concept. Many of the scientists struggled with this concept and then had difficulties to connect it to physics. Some of the scientists asked many questions to better understand it; others asked the interviewer to give an actual example of inserting the concept into the curriculum. Two of the participants gave an example referring to a work of colleagues who were chemists. These responses led us to discuss criticism of the conceptual framework in the Sec. V.

\section{B. An analysis of the suggested insertion points according to the middle school physics curriculum}

After a general presentation of the resulting insertion points, we will present the suggested insertion points with more details and representative examples. The physics middle school curricular concepts and topics will serve as a basis and the different grades as an organizing theme for the insertion points. Inserting the NST concepts was based on the curriculum because our aim was to insert the NST concepts into the physics curriculum and not the other way around.

Figure 4 presents a general overview of the insertion points for the different curricular topics. Almost all curricular topics had connections with NST essential concepts. There were three "hot" topics (namely, curricular topics with many insertion points): one in the 7th grade and two in the 8th grade (Fig. 4, orange) that together included two thirds of all insertion points. The topics are (1) inquiry skills (7th grade), (2) electric and magnetic forces, and (3) mechanical forces (8th grade). Two topics from the 7th grade had almost no connections: (1) quantitative tools, and (2) representation of data. These "cold" topics (highlighted in blue, Fig. 4) have a strong mathematical component and deal with formulating physical phenomena and visualizing measured data, respectively.

\section{7 th grade}

In the 7th grade, students are formally exposed to the physics framework of concepts and skills for the first time 


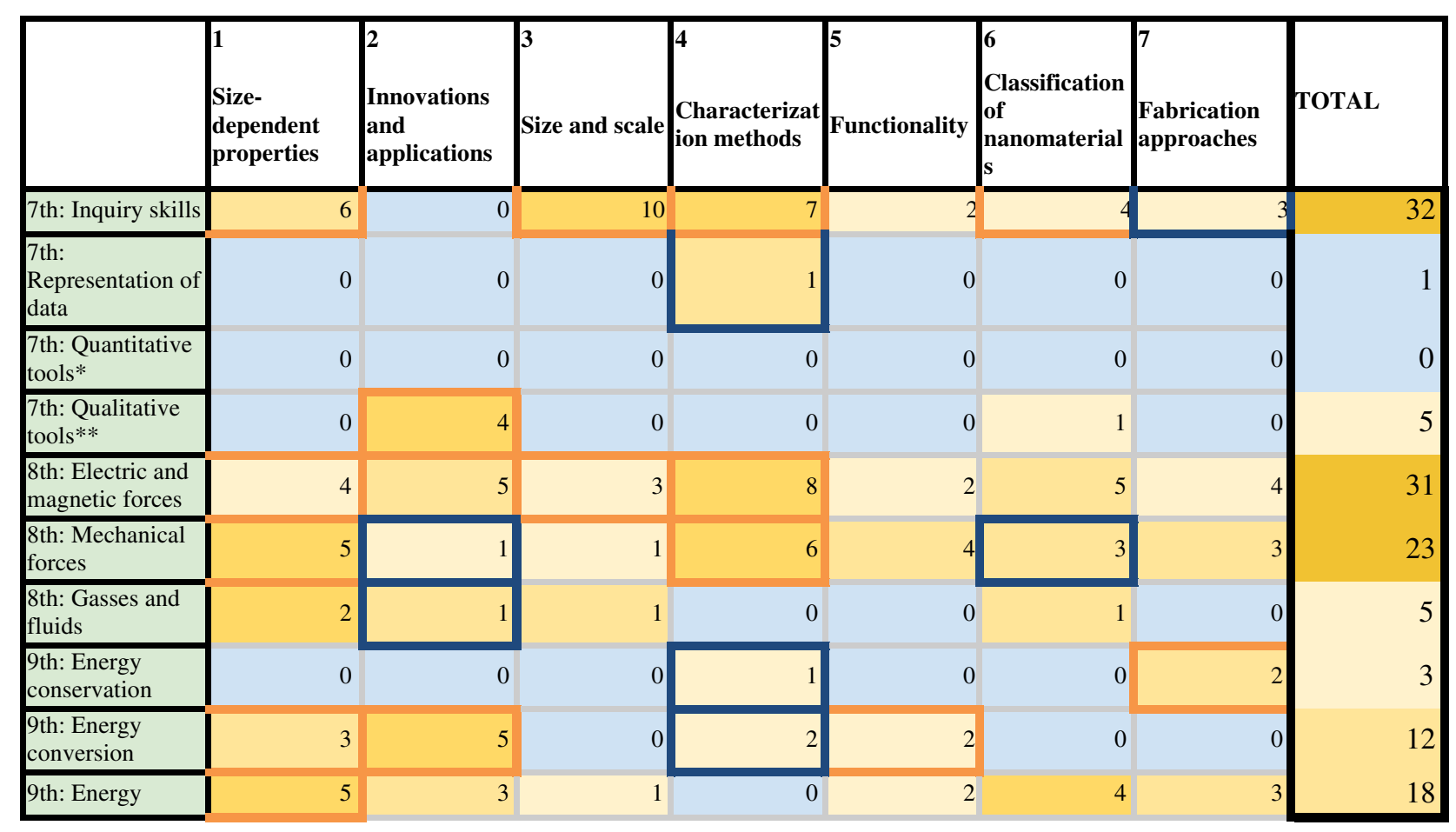

FIG. 4. "Heat map"- the number of connections made between NST concepts and specific curricular topics. A "warmer" color (more orange) indicates more insertion points per concept and topic. Bold orange frames represent connections that were strongly supported by the teacher during the validation process. Bold blue frames represent connections the teacher opposed. No frame means the teacher agreed with the insertion point but did not make any comment on the connection during the validation process. *Quantitative tools: representing physical phenomena by formula or other mathematical expressions, for example, velocity, $V=\Delta x / \Delta t$. $* *$ Qualitative tools: representing or describing physical phenomena by using natural laws. Example: the energy conservation law and how we can use it to predict in words the motion of a ball thrown vertically.

and become familiar with the discipline. The first curricular topic, "inquiry skills," deals with basic physics concepts, measurement, and accuracy, size, and scale. This topic received the most connections of all curricular topics, almost $25 \%$ of all connections (Fig. 4).

As seen in Fig. 4, the hot NST concepts connected to this topic are (3rd) "size and scale," which is also an actual curricular topic and (4th) "characterization methods," which is synonymous to measurement. Most of the examples that were given had a similar idea of comparing properties or characterization methods starting from bulk size to nano size.

Other 7th grade topics had a relatively small number of connections (Fig. 4). A strong connection that appeared was between the topic "qualitative tools" and the (2nd) NST concept of "innovations and applications of nanotechnology." Scientists that suggested these connections aimed to show how nanoscience is implemented in everyday life by becoming a product or technology. They referred to the topic of qualitative tools because their explanation consisted of cause and effect, which provided a sense of the nature of the science behind every implementation without using numbers or a formula (see an example in Table IV in Appendix B, 2nd column).

\section{8 th grade}

The 8th grade was the most connected, compared with the other grades, with the two hot topics of "mechanical forces" and "electric and magnetic forces" that when combined comprised almost $42 \%$ of all connections (Fig. 4). Both topics were connected to all the NST concepts, thus proving to be suitable for integrating NST into middle school physics. Within the insertion points of these two topics, we found a variety of suggestions regarding how to actually conduct the insertion in class, e.g., thinking schemes, class demonstrations, and hands-on experiments. There were also examples that compared the nanoscale to bulk, but they were mostly limited to concepts that are connected to this kind of example, e.g., (1st) "sizedependent properties." The concept (4th) "characterization methods" is a hot concept for both topics. With the curricular topic of mechanical forces, all 6 connections referred to the atomic force microscope (AFM) as a suitable method for use with students at this stage. For electric and magnetic forces there were several suggestions for methods such as magnetic force microscope (MFM), electric force microscope (EFM), and scanning probe microscope (SPM). Scientists claimed that all these identification methods could be qualitatively explained based on students' 
knowledge of forces. Moreover, the scientists emphasized that both the topics "different forces" and "interactions" are the main principle behind characterization methods.

For the curricular topic "fluids and gasses" the scientists suggested connections (Appendix B) suitable for the small part it plays in the curriculum. Most of the examples refer to different behaviors of nanoparticles in fluids, mostly water.

\section{9th grade}

The 9th grade topics deal with energy. In presenting this topic to scientists, we used two main topics: conversion and conservation of energy (Fig. 2, Appendix B, Tables VIII-IX), which are how the topic of energy is taught in the 9th grade [15]. Many scientists faced difficulties relating the connections they made to one of the two topics of energy and just indicated that their explanatory story relates to energy as a general term. We therefore decided to add a third energy topic, which is neither conversion nor conservation (Appendix B, Table X) and stands on its own. Surprisingly, this topic received many examples (18 out of a total of 33 examples related to energy), many of which were about discrete properties or discrete behavior of energy at the nanoscale. Most of the scientists avoided mentioning quantum mechanics explicitly but did refer to some of its features in relation to the topic of energy. The NST concept (1st) "size-dependent properties" had a naturally strong connection here due to the appearance of the energy-related quantum phenomena starting from the nanoscale and below.

The topic of energy conservation received a very small number of connections (3), mostly relating to the 7th NST concept of "fabrication approaches" and "self-assembly to thermodynamics." The topic of energy conversion was found to be more relevant and 12 insertion points were suggested, mostly on heat-related issues. Note that the more interesting and complete examples for insertion points were not connected to these two (curricular) topics of energy.

\section{C. "The voice of the teacher": Openly discussing the results with a middle school science teacher during the validation stage}

After presenting the teacher with the methodology of the discourse with the scientists and the obtained tables of insertion points, she began to mark the insertion points and to present her comments and concerns. Some of the scientists' suggestions triggered intense discussions on possible challenges about actually implementing them in middle school science teaching (Fig. 4, blue frame). Other connections were received with support and even enthusiasm (Fig. 4, orange frames). Examination of Fig. 4 shows that the blue frames (teachers' negative comments on scientists' connections) do not appear on any of the hot topics and mostly refer to connections that the scientists considered weak. Many of the hot topics received positive comments from the teacher (Fig. 4, orange frame). These positive comments were mostly about connections and examples being interesting, important, and motivating for students.

The negative comments received by the teacher are centered around three main themes:

1. The example or connection is too difficult for middle school level.- "Yes you can mention the laser but not really teach how it works. This is too much for students at this level. Maybe as an enrichment topic for advanced students" (on connecting 9th grade energy conservation topics to using a laser for characterization).

2. The example or connection is not really related to the curriculum.- "I can't really see the connection between this example and the curricular topics" (on connecting 8th grade topics on gasses and fluids to the innovations and applications concept by the example of nanoparticles' antibacterial properties).

3. The example or connection contains a mixture of several NST concepts, or it can be more suitable for a different NST concept.- - "This example could work here but I think it is more suitable for sizedependent properties." (on connecting the 7th grade mechanical forces topic to the innovations and applications concept by the example of nanoparticlebased lubricants).

The teacher raised additional general concerns about inserting NST into the curriculum in the last reflective part of the discourse. The main concerns are related to science teachers' perspective towards contemporary science and a gap that they may have in content knowledge and also regarding their motivation to update their knowledge and teaching methods. She offered to approach this by establishing context-based learning communities and open courses for teachers to address these needs.

\section{DISCUSSION}

In discussing these results, we first looked back to the initial research questions: What are the suggested insertion points for NST concepts in a middle school physics curriculum? We can see that from the perspective of the physics middle school topics, the participating scientists were able to provide connections $(N=130)$ for all concepts and grades. This was not without difficulties with certain topics, but approaching scientists with this question instead of middle school teachers provided a richer set of connections, which includes all NST concepts [8,12]. This success emphasizes the need for strong contemporary content knowledge and a deep understanding of basic physics to perform the task of connecting these two different conceptual fields. Scientists' statements, presented in the Results section, indicate doubt and later reflection regarding the scientists' own ability to make connections between a contemporary science topic and a middle school science curriculum. This gap between their initial 
perception and the final result sheds a different light on this exercise. This points to a process of training for making connections between contemporary science concepts and curricular concepts as a tool to promote scientists' communication of science, which is analyzed and described by a different study [16].

\section{A. Criticism of the conceptual framework}

During the stage of suggesting insertion points in the interview, scientists often commented on specific NST concepts or the entire list. Their comments often criticized the connection of a certain NST concept to the physics discipline or even questioned the coherency of the list of the seven NST essential concepts. For example, the difficulty caused by the 5 th concept (functionality), as mentioned in Sec. IV, triggered a comment that related to the entire list: "Somehow this list is hard for me to use because it is a chemists' list." (scientist A). Another comment by a different scientist, which was triggered by this concept, referred to the nature of the concept itself "..functionality is where chemistry has a real distinction from other scientific disciplines. I don't see how physics belongs there.." (scientist B). These comments, which were echoed in other interviews as well, attributed this list and specific concepts to the chemistry discipline, by claiming physicists "don't speak this way." Another example, referred to the first concept (size-dependent properties) “..as a physicist I wouldn't say 'size-dependent properties' but instead, 'size-dependent phenomena.' Physicists are not interested in properties" (scientist C). Another type of criticism targeted the internal coherency of the list; for example, "I'm not sure I agree with these seven concepts, it's like mixing apples and oranges, it's not the same thing. Innovations and applications are not the same as the scientific concepts you want to teach" (scientist A). Scientists were informed that the list of seven concepts was formulated by a multidisciplinary group but still they had criticism and negative comments. Apparently, the list did not relate to many of them as physicists.

Another point of criticism regarding the framework was not as explicit-it resembled a lack of confidence that experts displayed in working with the curricular topics. For example, at the beginning of a discourse, scientists were often pessimistic about finding connections, claiming that NST or contemporary science is too complicated to be explained in a middle school context. After the curriculum was presented, along with guidance in understanding the NST concepts and the task of connecting, scientists were often surprised about their own ability to make and rationalize connections: "I thought I had nothing to say to middle school students or teachers, but now I see that I can..." (scientist $C)$.

The other criticism received from the experts regarding the structure of the list of essential concepts from the physics point of view raises some more questions regarding the multidisciplinary approach of the list. Using a multidisciplinary list in a discussion that is restricted to the physics curriculum is presently our only option [4]. It may be appropriate to derive from the list different versions that use the language of specific disciplines such as physics, chemistry, or earth sciences. This may support us in finding more and deeper connections between NST and a specific discipline [17].

Three additional points for discussion refer to results related to specific concepts from NST and specific topics of middle school physics. These results are related to the research question that refers to the nature of the connections:

(1) The curricular topics quantitative methods and representation of data received 0 and 1 connections, respectively, out of 130 that were suggested by the scientists. Scientists often referred in the discourse to these quantitative subjects as essential for understanding contemporary science. This position is also supported by physics education studies $[18,19]$ that was centered on modeling of nature and the use of mathematical and pictorial representations. In the Israeli educational system, teachers often view proficiency in high-level mathematics as a necessary condition for physics studies at a high-school level. Nevertheless, we found that out of the 130 connections raised by experts, there was no reference to specific formula and almost no reference to other quantitative representations of science.

(2) The curricular topics of energy in the 9th grade are traditionally divided into conversion and conservation [15]. These topics were moderately referred to by the scientists, making 12 and 3 connections, respectively. However, 18 other connections did not belong in one of these two categories and referred to other aspects related to energy. This result is supported by recent work done on the concept of energy and the differences between the way it is being taught in secondary school and the way scientists and the popular science press use it [20]. This raises a question regarding the way we traditionally teach the concept of energy in secondary school physics and whether it supports an understanding of energy related to popular and contemporary science topics.

(3) Two of the NST essential concepts dominated the 130 connections, receiving 25 connections each: (1st) size-dependent properties and (4th) characterization methods (Fig. 3). Characterization methods as a concept was also mostly used by scientists as a main theme to describe their personal research, as was shown in a science communication analysis of these talks [16]. In addition, in a course for inservice chemistry teachers, which was based on the 7 NST concepts, it was shown that characterization methods was most frequently used by teachers in 


\begin{tabular}{|c|c|c|c|c|c|c|c|}
\hline \multirow{2}{*}{$\begin{array}{l}\text { 8th Electric } \\
\text { and } \\
\text { magnetic } \\
\text { forces }\end{array}$} & 1 & 2 & 3 & 4 & 5 & 6 & 7 \\
\hline & $\begin{array}{l}\text { Size- } \\
\text { dependent } \\
\text { properties }\end{array}$ & $\begin{array}{l}\text { Innovations } \\
\text { and } \\
\text { applications }\end{array}$ & Size and scale & $\begin{array}{l}\text { Characterization } \\
\text { methods }\end{array}$ & Functionality & $\begin{array}{l}\text { Classification } \\
\text { of } \\
\text { nanomaterials }\end{array}$ & $\begin{array}{l}\text { Fabrication } \\
\text { approaches }\end{array}$ \\
\hline $\begin{array}{l}\text { Connection } \\
\text { strength }\end{array}$ & Weak & Mid & Weak & Strong & Weak & Mid & Weak \\
\hline $\begin{array}{l}\text { General } \\
\text { description of } \\
\text { insertion } \\
\text { points }\end{array}$ & $\begin{array}{l}\text { Electric } \\
\text { properties at } \\
\text { the nanoscale } \\
\text { in relation to } \\
\text { different } \\
\text { scales }\end{array}$ & $\begin{array}{l}\text { Examples } \\
\text { from the } \\
\text { world of } \\
\text { nanoelectronic } \\
s\end{array}$ & $\begin{array}{l}\text { Electric and } \\
\text { magnetic } \\
\text { properties at } \\
\text { the nanoscale }\end{array}$ & $\begin{array}{l}\text { Electric and } \\
\text { magnetic } \\
\text { properties of } \\
\text { characterization } \\
\text { devices }\end{array}$ & $\begin{array}{l}\text { Changing and } \\
\text { measuring } \\
\text { electric } \\
\text { surface } \\
\text { properties }\end{array}$ & $\begin{array}{l}\text { Explaining } \\
\text { conductivity } \\
\text { and electric } \\
\text { forces using } \\
\text { dimensionality } \\
\text { - conduction } \\
\text { in many } \\
\text { dimensions }\end{array}$ & $\begin{array}{l}\text { Self-assembly } \\
\text { by electric } \\
\text { interactions }\end{array}$ \\
\hline Example 1 & $\begin{array}{l}\text { "You want } \\
\text { machines to } \\
\text { work faster, } \\
\text { you want } \\
\text { electrons to } \\
\text { move faster } \\
\text { from one } \\
\text { place to } \\
\text { another, and } \\
\text { to do that you } \\
\text { need to } \\
\text { shorter the } \\
\text { length." }\end{array}$ & $\begin{array}{l}\text { "When you're } \\
\text { introducing } \\
\text { electric } \\
\text { circuits at } \\
\text { some point, } \\
\text { you can ask: } \\
\text { OK, if I could } \\
\text { make an } \\
\text { electric circuit } \\
\text { smaller and } \\
\text { smaller, } \\
\text { would it make } \\
\text { a difference?" }\end{array}$ & $\begin{array}{l}\text { "We can talk } \\
\text { about } \\
\text { magnetic } \\
\text { domains and } \\
\text { explain hard } \\
\text { drives; the } \\
\text { smaller it is, } \\
\text { the more } \\
\text { memory we } \\
\text { have in the } \\
\text { same sized } \\
\text { hard drive." }\end{array}$ & $\begin{array}{l}\text { "We can } \\
\text { reduce our } \\
\text { world, which is } \\
\text { a world } \\
\text { consisting of } \\
\text { millimeters and } \\
\text { the world that } \\
\text { consists of } \\
\text { nanometers by } \\
\text { building very } \\
\text { accurate } \\
\text { needles and by } \\
\text { very accurate } \\
\text { measurement } \\
\text { of electric } \\
\text { forces, which } \\
\text { your needle } \\
\text { experiences } \\
\text { while it moves } \\
\text { distances of } \\
\text { nanometers." }\end{array}$ & $\begin{array}{l}\text { "Light } \\
\text { detectors- if } \\
\text { the surface } \\
\text { conducts, then } \\
\text { it won't work } \\
\text { because you'll } \\
\text { always have } \\
\text { current going } \\
\text { through the } \\
\text { detector. So, } \\
\text { you do } \\
\text { passivation." }\end{array}$ & $\begin{array}{l}\text { "Two- and } \\
\text { three- } \\
\text { dimensional } \\
\text { materials. } \\
\text { Many } \\
\text { functions like } \\
\text { conductivity- } \\
\text { shrink the } \\
\text { materials' } \\
\text { dimensions } \\
\text { and increase } \\
\text { strength and } \\
\text { conductivity." }\end{array}$ & $\begin{array}{l}\text { "Self- } \\
\text { assembly: it's } \\
\text { because of } \\
\text { electric forces } \\
\text { and dipole- } \\
\text { dipole } \\
\text { interactions. If } \\
\text { you give it } \\
\text { enough time, } \\
\text { it will become } \\
\text { a stable state, } \\
\text { which is self- } \\
\text { assembly. At } \\
\text { this scale } \\
\text { these } \\
\text { interactions } \\
\text { build the } \\
\text { world". }\end{array}$ \\
\hline Example 2 & $\begin{array}{l}\text { "Charges are } \\
\text { separated at } \\
\text { this scale and } \\
\text { the reason we } \\
\text { don't feel } \\
\text { them is } \\
\text { because they } \\
\text { screen out } \\
\text { each other. } \\
\text { Therefore, } \\
\text { most of the } \\
\text { time } \\
\text { everything is } \\
\text { neutral. At the } \\
\text { nanoscale } \\
\text { nothing is } \\
\text { neutral." }\end{array}$ & $\begin{array}{l}\text { "Quantum } \\
\text { dots and } \\
\text { artificial light- } \\
\text { efficiency and } \\
\text { brighter TV } \\
\text { screens" }\end{array}$ & & $\begin{array}{l}\text { "In a blood } \\
\text { count you take } \\
\text { your blood and } \\
\text { flow it in the } \\
\text { tube through a } \\
\text { small orifice of } \\
\text { which you } \\
\text { measure the } \\
\text { current. } \\
\text { Changes in the } \\
\text { current are due } \\
\text { to the size of } \\
\text { the cells, so } \\
\text { you can know } \\
\text { their size and } \\
\text { identify them } \\
\text { by size and } \\
\text { quantity, which } \\
\text { is the blood } \\
\text { count. Cells are } \\
\text { micron in size. } \\
\text { But what } \\
\text { happens when } \\
\text { you want to } \\
\text { count proteins? } \\
\text { You decrease } \\
\text { the size of the } \\
\text { tube and orifice } \\
\text { to the size you } \\
\text { want to } \\
\text { measure". }\end{array}$ & & & \\
\hline
\end{tabular}

FIG. 5. A qualitative description of the NST context that was connected to a curricular topic by a concept with representative examples. Classification for "weak," "mid," and "strong" connections was made relative to the overall number of connections found for each topic (the numbers are presented in Fig. 4). For example, 31 connections were given for " 8 electric and magnetic forces." There was an average of 4.42 connections per NST concept. If a concept received 4 or 5 connections (around the average), it was classified as "mid". If it received less than 4, it was classified as "weak," more than 5, as a "strong" connection. 


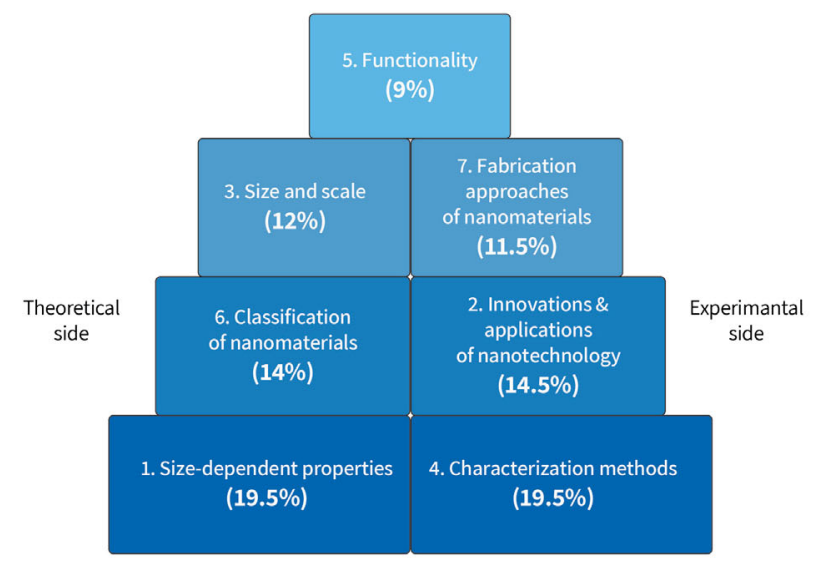

(a)

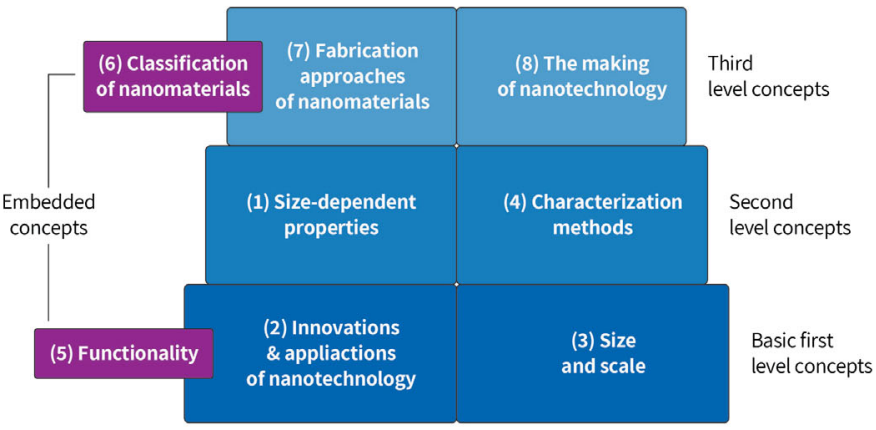

(b)

FIG. 6. Comparison of the study results to previous studies according to the hierarchical structures of the 7 NST essential concepts. (A) Constructed by the percent of connections given by the experts in this study (the percent in brackets). It is divided into two sides according to the theoretical, experimental nature of the context given by experts for the connections. (B) Constructed according to a review of NST secondary education literature [22]; this scheme includes an 8th concept that is not used in the current study (the making of nanotechnology).

their online assignments [21]. From all these different perspectives, the 4th concept characterization methods stands out from the list. Taking these results one step further, this concept might serve as a bridge between scientists, teachers, and the secondary science curriculum and may promote discussions of NST and maybe other contemporary science topics. We still lack the students' perspective regarding this concept in this context, but in other cases it has been shown that working with AFM and

TABLE II. Connections between middle school physics curricular topics (left) and NST essential concepts (top) that were found to be "strong" by a group of scientists and validated as suitable by a middle school teacher.

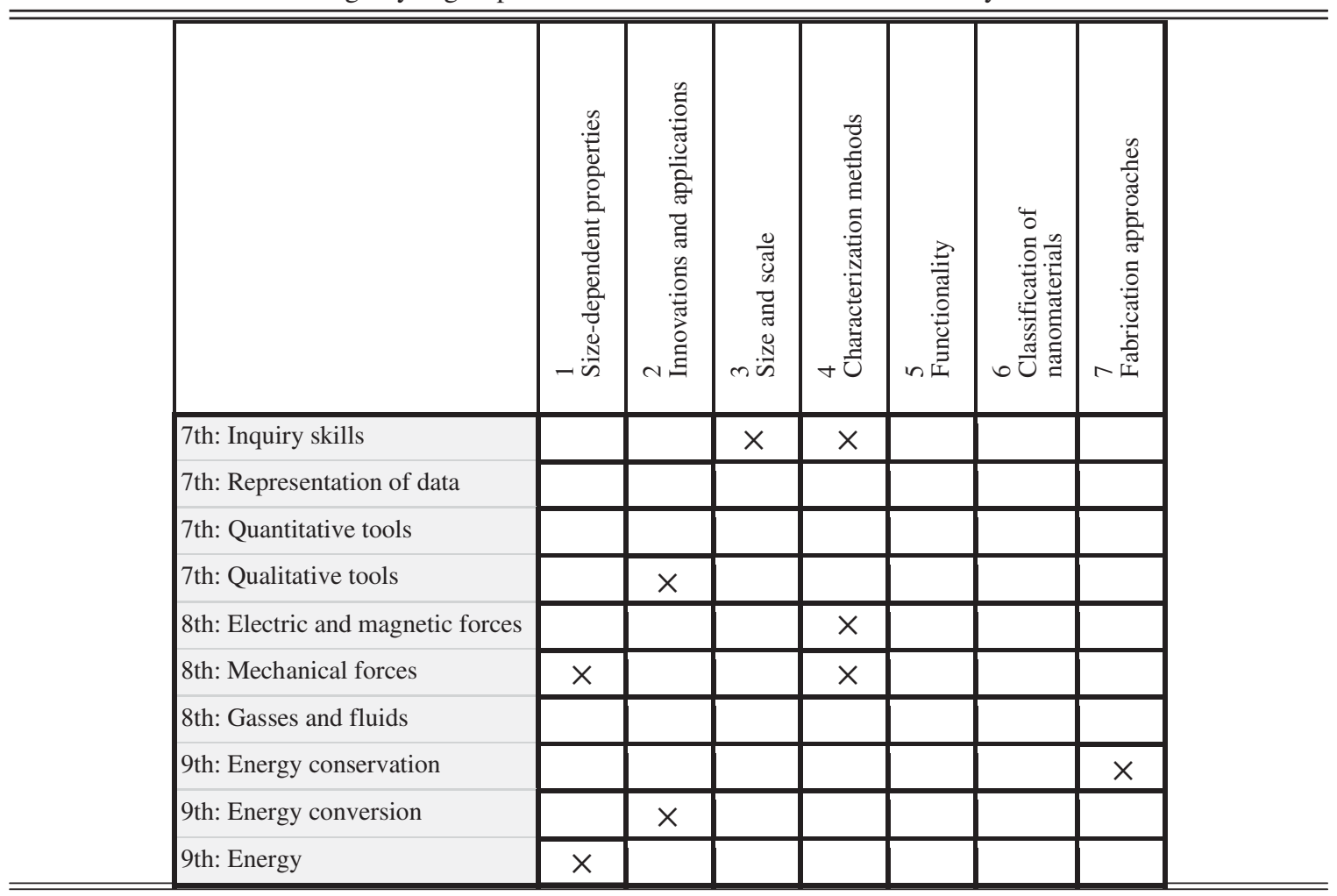


SEM was received well by students and promoted their interest and motivation to learn science [22].

The validation stage, carried out with a middle school teacher on the obtained connections, may shed light on which of these connections are practical for middle school teachers. It may also shed light on differences in perception between scientists and teachers regarding contemporary topics suitable for physics education in middle school. One must take into consideration that scientists are experts on the subject matter, on what is new and exciting in science today. However, teachers are experts on the reality of teaching science in school.

Another piece of evidence supporting the existence of a gap regarding scientists' and science educators' opinions is presented in Fig. 6. Figure 6 (left) shows a hierarchical structure that can be constructed based on the number of connections given by the scientists in this study. We believe that this structure represents the ability of the concept to result in contexts that refer to middle school physics topics. In a review by Blonder and Yonai [22] regarding studies of NST activities and projects related to secondary education, a similar type of hierarchy was constructed (Fig. 6, right). The placing of each concept in the structure was based on its appearance as a primary or secondary topic in secondary education activities.

These two structures disagree regarding the placement of concepts, meaning the concepts scientists had the most success with in connecting to the curriculum are not necessarily the ones that are used as a theme in NST secondary school-related activities. This gap should raise questions regarding selection of topics for secondary activities in a way that reflects the authentic point of view of expert scientists in the field. To bridge this gap, we suggest that future research and pedagogical work on insertion of NST topics into secondary physics education should focus on the hot topics that were positively validated by the teacher in this study (Table II).

\section{CONCLUSIONS}

In this study, we produced a rich set of connections between two scientific topics obtained by a process involving 12 experts in relevant scientific fields. The main points emerging from the analysis of these connections are presented in Sec. V. They can be used when program designers are planning NST-themed projects for secondary education as well as by other researchers that study NST education. In addition, the richness of the set is also reflected in the details of the explanatory stories (Appendix B, Tables III-X). These stories provided rationale for the connections and can be considered as a possible context for teachers in designing NST-inspired lesson plans or activities.

However, teachers still have to undergo a long process before they will be able to apply the results in their classrooms. The goal to enrich the traditional physics curriculum with contemporary topics by creating a road map that connects the existing material with new science topics has not yet been achieved. This research is a first step in its construction and implementation. Teachers should be supported and encouraged to follow this road map in their classes and lead their students accordingly. These results may serve as a contextual basis for designing an academic course or a professional development program for teachers to update their contemporary science knowledge in a way that will help them connect this knowledge to their practice. We also suggest that an integral part of such a course or program would be the development of a pedagogy suitable for using these materials with the teachers. This may contribute to teachers' motivation to bring these materials into their classrooms [23]. For extended support, we suggest that a NST context-based community of practice be formed in which teachers that engage with these topics can work together in developing teaching methods, reflecting on the teaching process, and facing the challenges of teaching contemporary science together. These suggestions for implementing the results should be accompanied by academic research that examines the effectiveness of the suggested approach for science teaching and science teachers.

Finally, the main goal established here was to promote contemporary science contexts in secondary physics education. This work may contribute to those that share this goal by large- or small-scale interventions in practice or research. The goal of eventually connecting novel contemporary science and technology to secondary science topics can provide students with a more authentic view of the science field and can open the door for students to eventually participate more effectively and knowledgeably in the science community.

\section{APPENDIX A: ID CARD OF 7 ESSENTIAL NST CONCEPTS}

1st concept: Size-dependent properties:

ID card definition: The changing properties of material as a function of size: the SA/V ratio, defects, quantum and optical properties.

Frontal comments: What is so special about the nanosized world? The uniqueness of nanotechnology.

2nd concept: Innovations and applications of NST:

ID card definition: Implementation of nanoscience for everyday use: ethical issues and benefits.

Frontal comments: Current and future applications Illustrate the real, unmet need for multidisciplinary approaches. Connections to "real life" subjects are believed to be important for students' motivation.

3rd concept: Size and scale:

ID card definition: Introducing the nanometer size, the need for miniaturization and its benefits.

Frontal comments: Students do not always understand the nano size and scale with a ratio in relation to the scales they are familiar with. This is something that is very clear 
and natural to scientists and teachers but very confusing for young students.

4th concept: Characterization methods:

ID card definition: Tools for studying, imaging, and manipulating the nanomaterials' size and their properties.

Frontal comments: SPM, STM, AFM, TEM, SEM, and other initials. After we understand the scale, it is important for children to understand the process that makes us "see" such small scales. Otherwise it is just a "black box full of magic.

5th concept: functionality:

ID card definition: A property that is provided for a material or a specific area in it. It transforms nanomaterials to be part of technology.

Frontal comments: The way we use or manipulate the properties of nanomaterials to our technological advantage. 6th concept: Classification of nanomaterials:

ID card definition: Categorization by different characteristics: type, conductivity, origin, and dimensionality.

Frontal comments: To understand that in nanotechnology the properties are determined not only by the substance and molecules that are used to fabricate the material but also by the dimensions of the particles that determine the electronic properties.

7th concept: Fabrication approaches:

ID card definition: The variety of options available for fabricating nanomaterials including self-assembly.

Frontal comments: Specifying in what ways we can build something whose size is a few hundred atoms, what is the difference between the bottom-up and top-down approaches? What is the physics of self-assembly? Why do atoms self-assemble? 


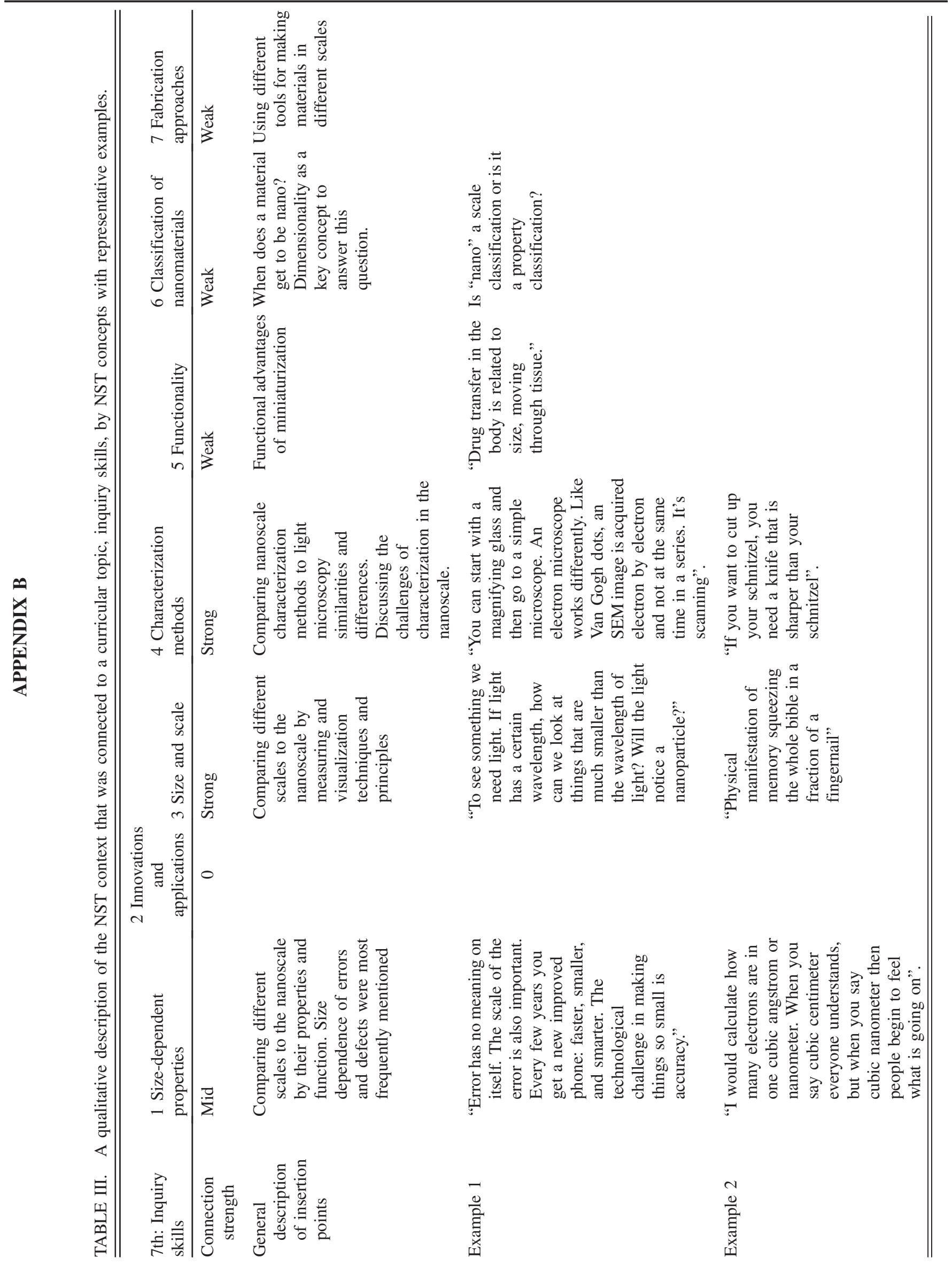




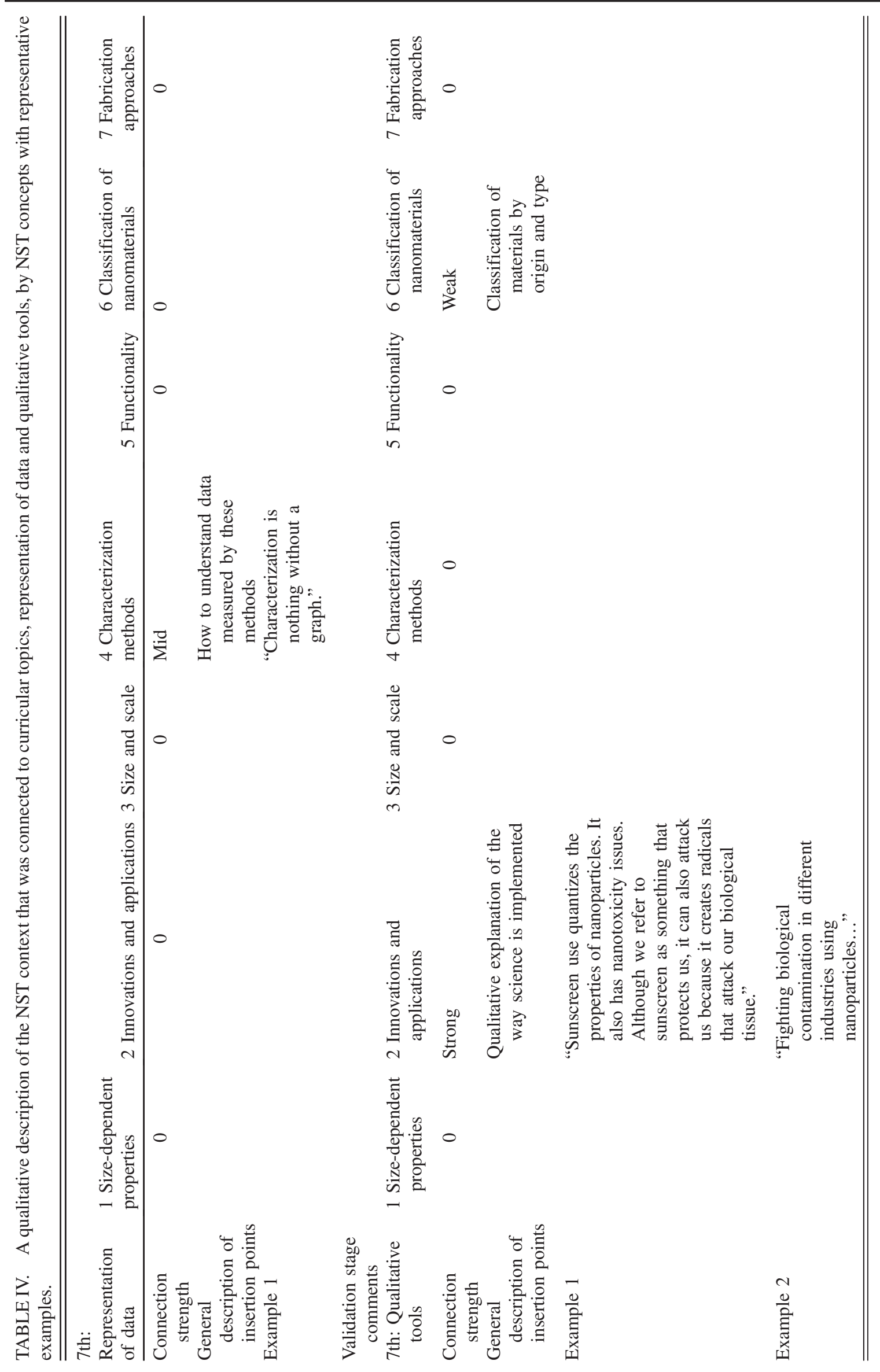




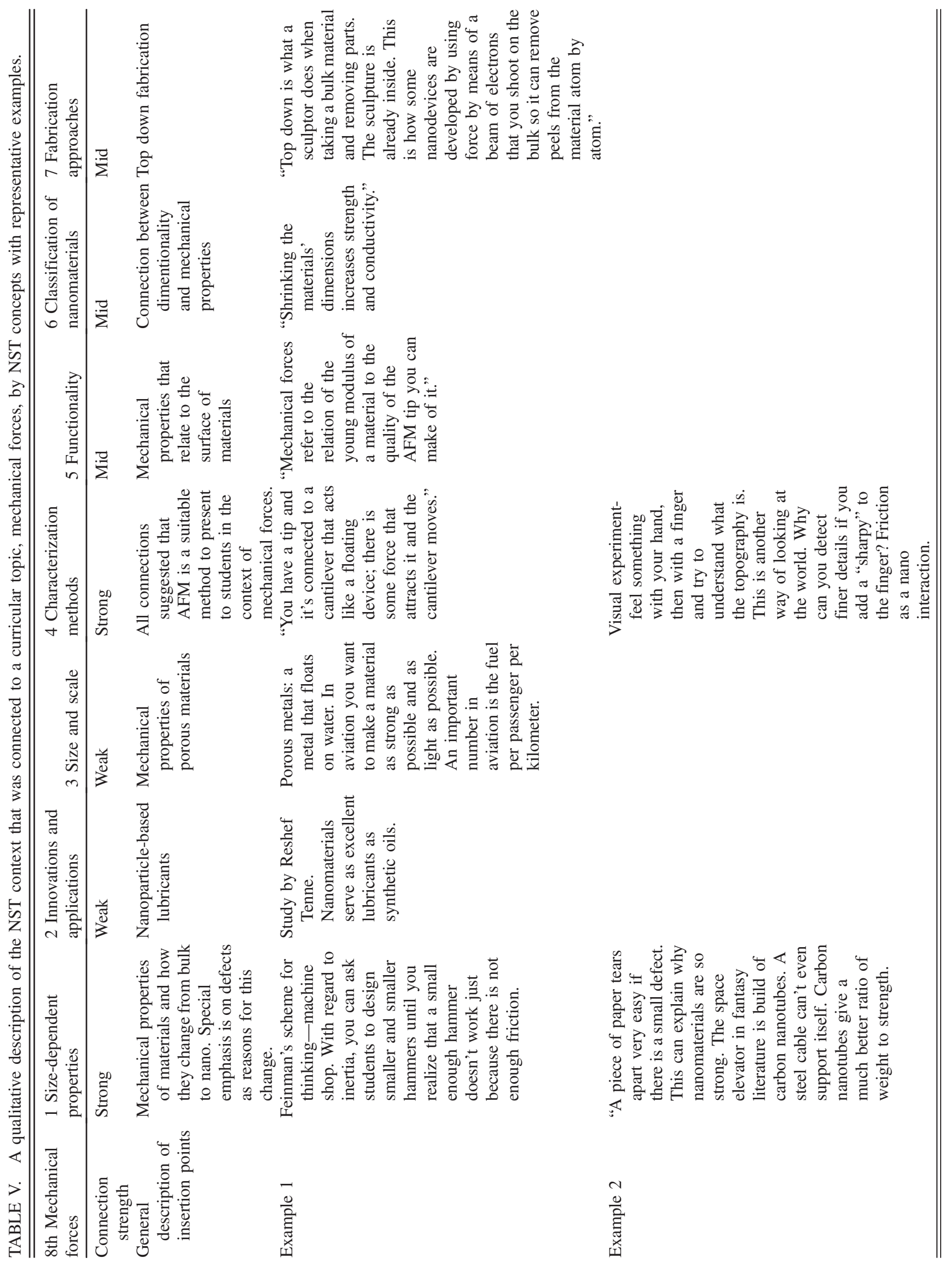




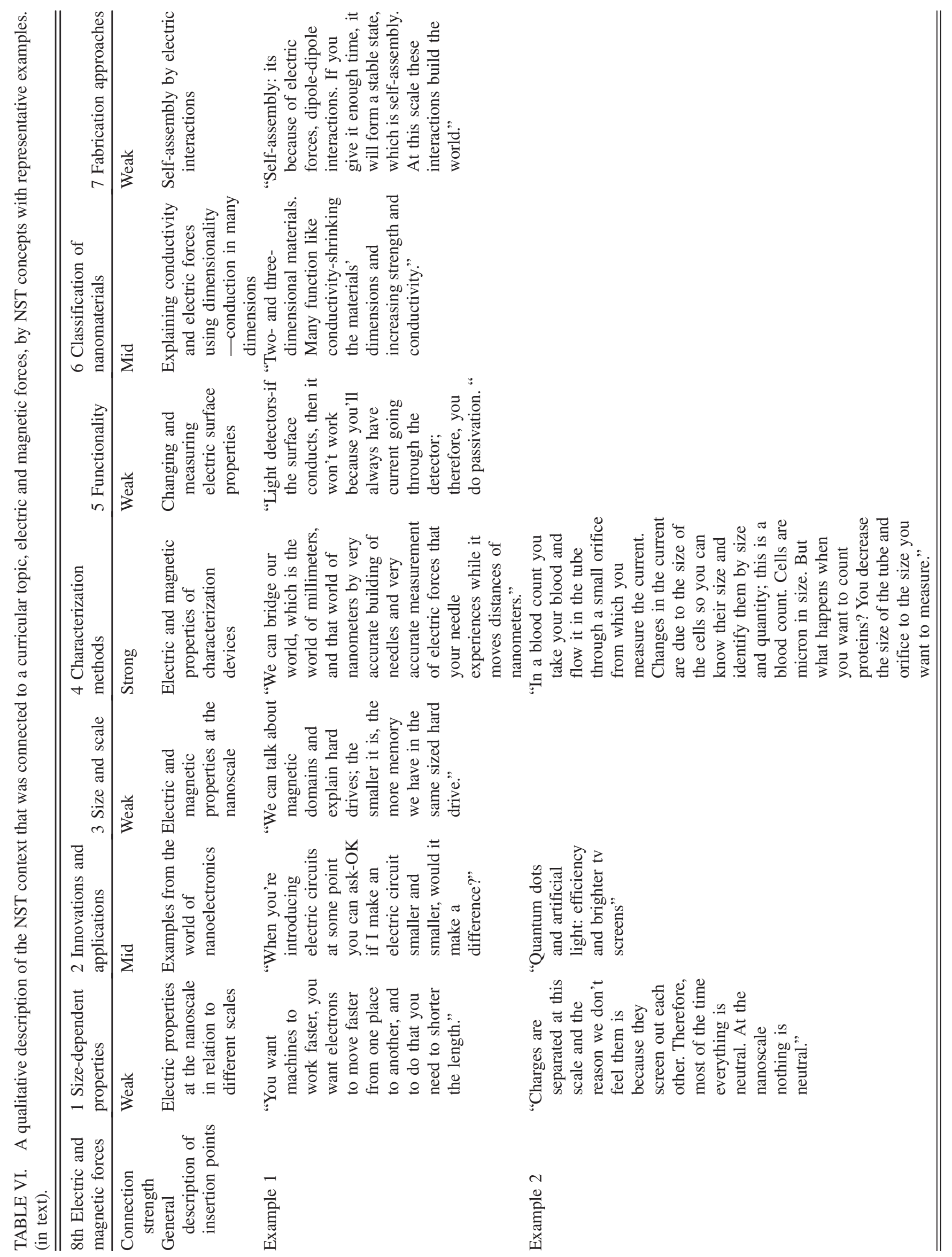



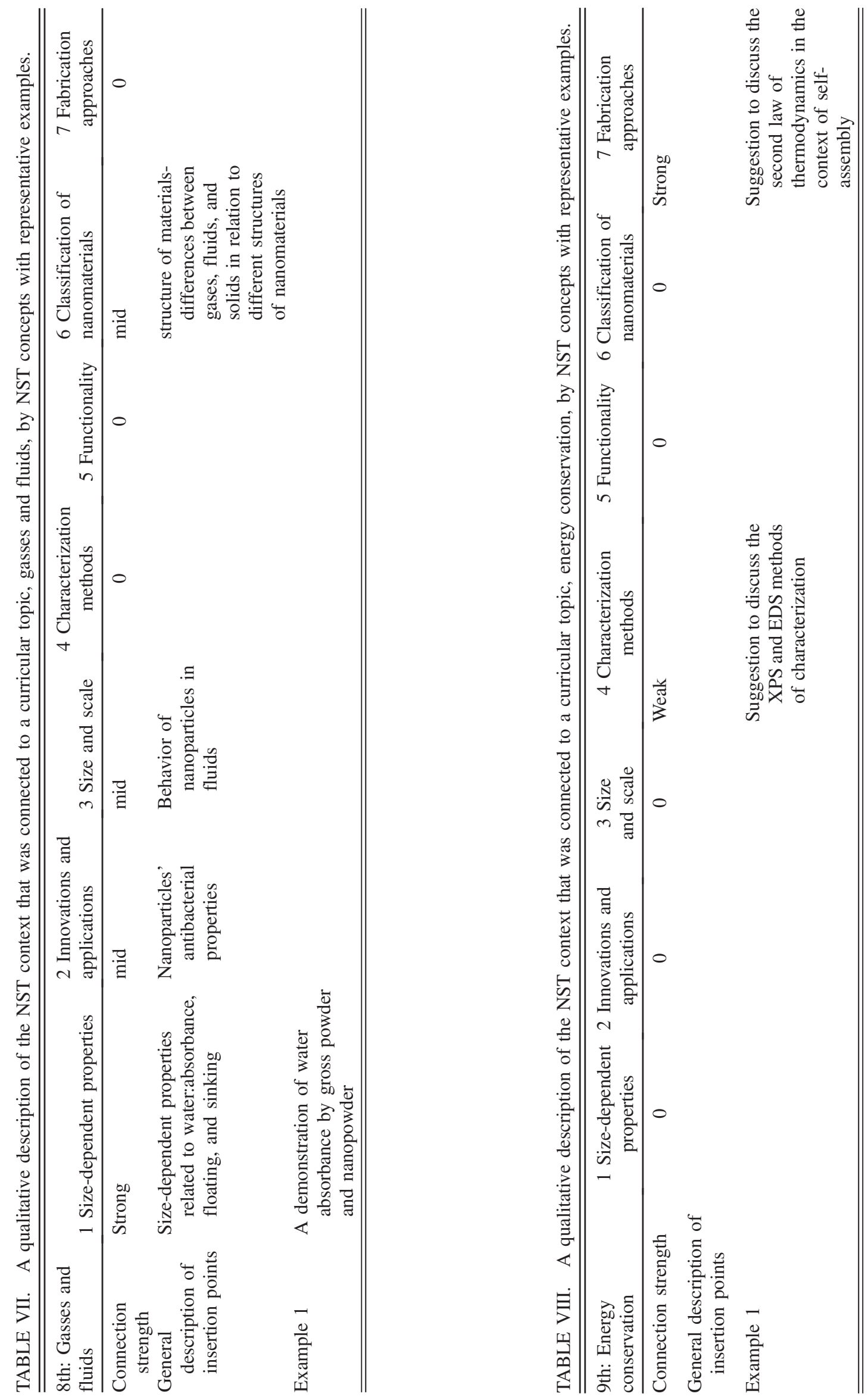


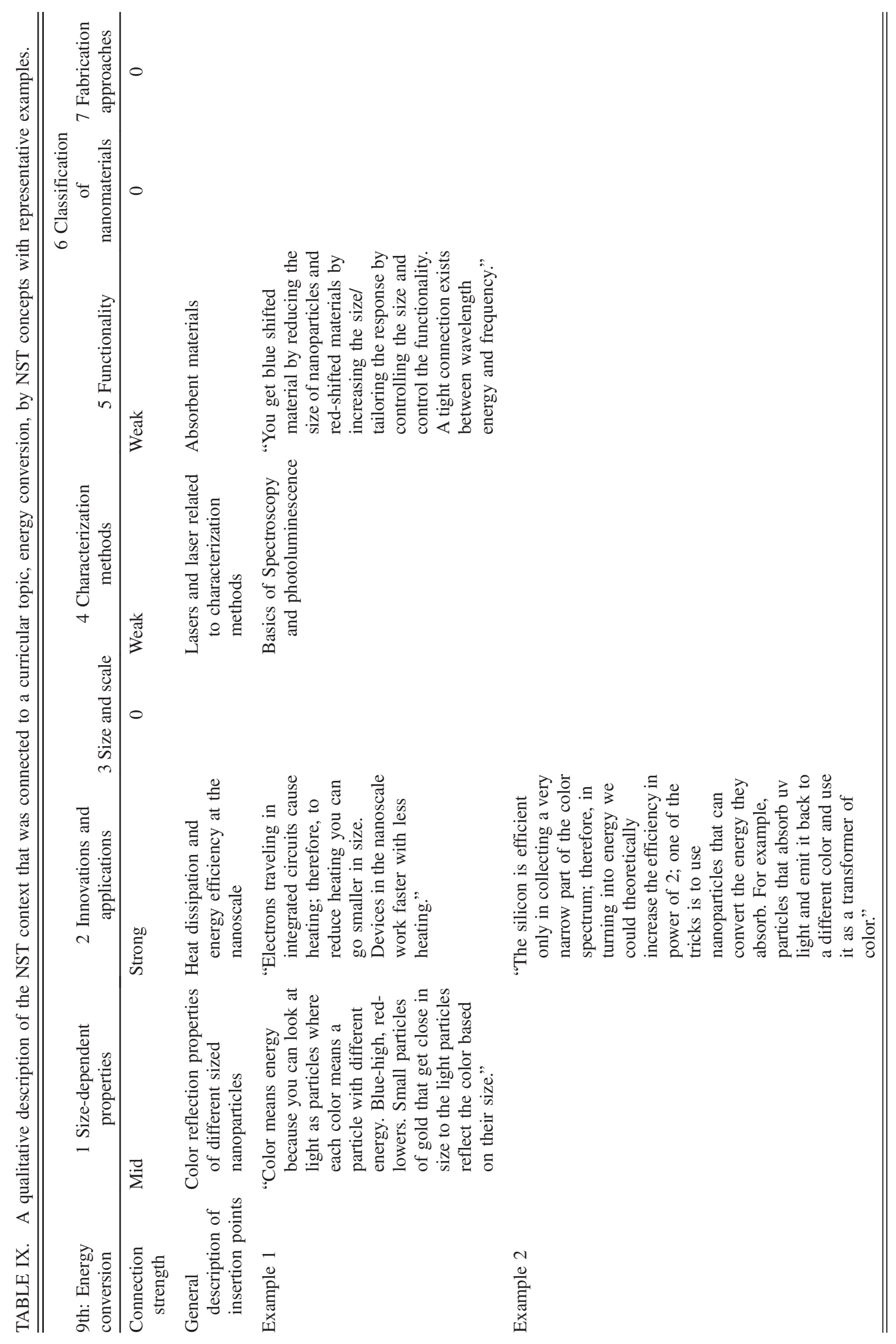




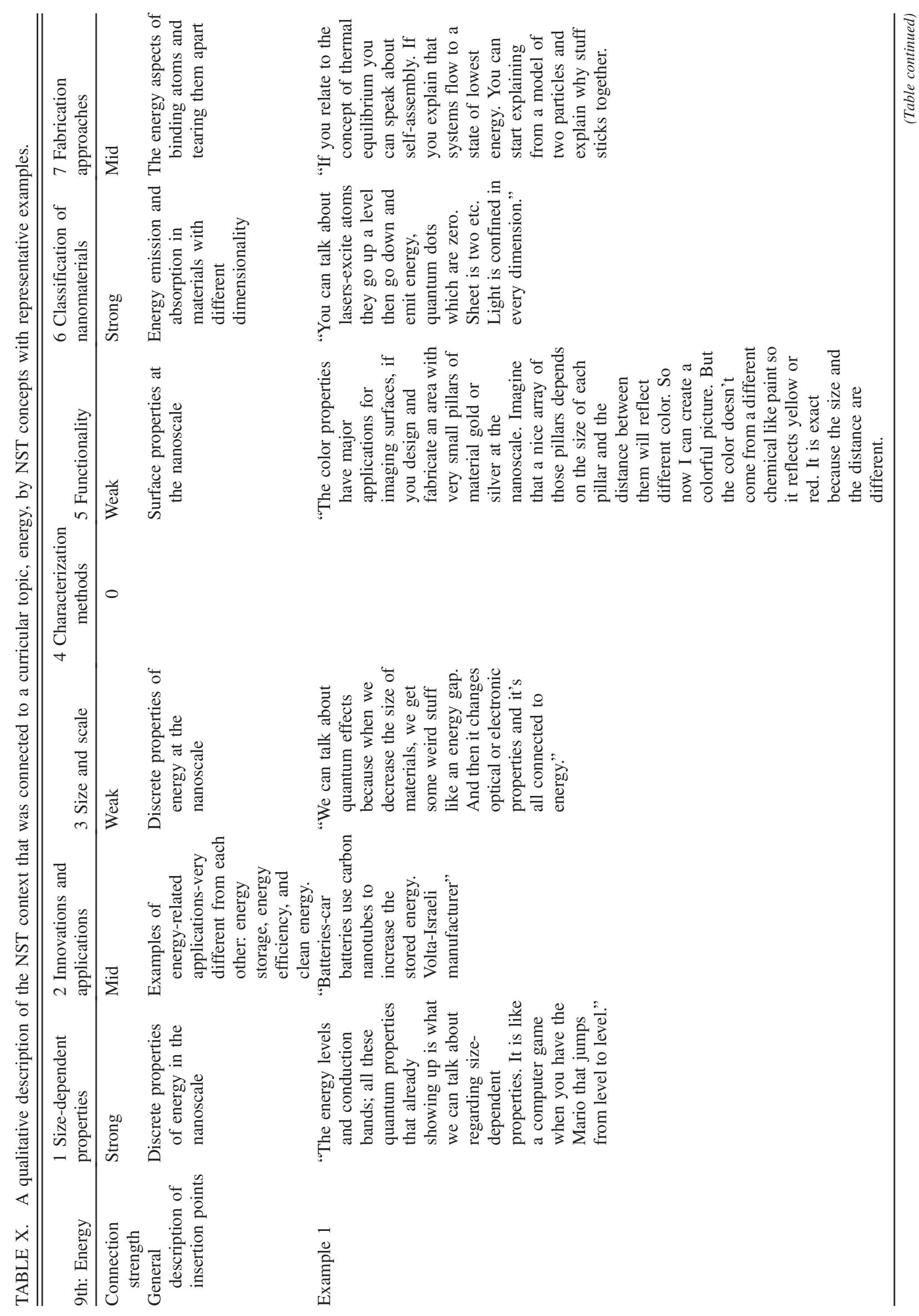




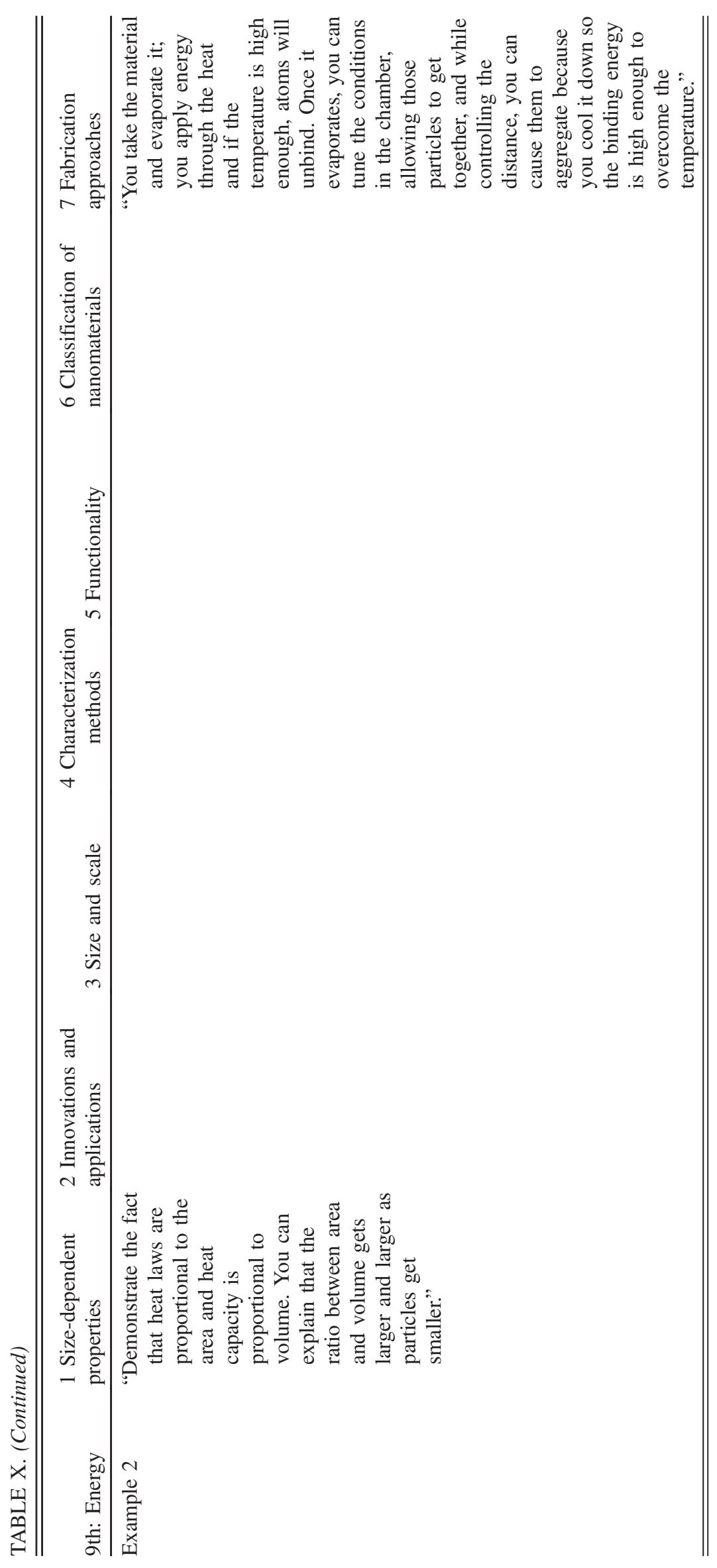


[1] L. A. Bryan, A. J. Magana, and D. Sederberg, Published research on pre-college students' and teachers' nanoscale science, engineering, and technology learning, Nanotech. Rev. 4, 7 (2015).

[2] M. G. Jones, R. Blonder, G. E. Gardner, V. Albe, M. Falvo, and J. Chevrier, Nanotechnology and nanoscale science: Educational challenges, Int. J. Sci. Educ. 35, 1490 (2013).

[3] M. C. Roco, From vision to the implementation of the U.S. national nanotechnology initiative, J. Nanopart. Res. 3, 5 (2001).

[4] S. Sakhnini and R. Blonder, Essential concepts of nanoscale science and technology for high school students based on a Delphi study by the expert community, Int. J. Sci. Educ. 37, 1699 (2015).

[5] J. W. Murry, Jr. and J. O. Hammons, Delphi: A versatile methodology for conducting qualitative research, Rev. High. Educ. 18, 423 (1995).

[6] R. Blonder and S. Sakhnini, The making of nanotechnology: exposing high-school students to behind-the-scenes of nanotechnology by inviting them to a nanotechnology conference, Nanotech. Rev. 4, 103 (2015).

[7] A. L. Kähkönen, A. Laherto, A. Lindell, and S. Tala, Interdisciplinary nature of nanoscience: Implications for education, Global Perspectives of Nanoscience and Engineering Education (Springer, Cham, 2016), pp. 35-81.

[8] S. Sakhnini and R. Blonder, Insertion points of the essential nanoscale science and technology (NST) concepts in the Israeli middle school science and technology curriculum, Nanotech. Rev. 7, 373 (2018).

[9] S. Kapon, U. Ganiel, and B.S. Eylon, Explaining the unexplainable: Translated scientific explanations (TSE) in public physics lectures, Int. J. Sci. Educ. 32, 245 (2010).

[10] S. Kapon, U. Ganiel, and B. Eylon, Scientific argumentation in public physics lectures: bringing contemporary physics into high-school teaching, Phys. Educ. 44, 33 (2009).

[11] Ministry of education cite, Israel (n.d.). Retrieved April 01, 2017, from http://meyda.education.gov.il/files/Mazkirut_ Pedagogit/MadaTechnologya/tochnit_phizika.pdf.

[12] R. Blonder and S. Sakhnini, Finding the connections between a high-school chemistry curriculum and nano-scale science and technology, Chem. Educ. Res. Pract. 18, 903 (2017).

[13] A. Shkedy, The Meaning behind the Words: Methodologies of Qualitative Research: Theory and Practice (The Hebrew University of Jerusalem, Jerusalem, 2012).

[14] S. McDonald, K. Daniels, and C. Harris, Cognitive mapping in organizational research, Essential Guide to Qualitative Methods in Organizational Research (2004), pp. 73-85.

[15] Education, T.I.m.o. Education program for Science and Technology http://cms.education.gov.il/EducationCMS/ Units/Tochniyot_Limudim/science_tech/Tochnit Meodkenet/chatab.htm (2015).

[16] E. Yonai and R. Blonder, USE YOUR OWN WORDS! Developing science communication skills of NST experts in a guided discourse, Int. J. Sci. Educ, Part B https:// doi.org/10.1080/21548455.2020.1719287 (2020).

[17] N. Quirola, V. Marquez, S. Tecpan, and S. E. Baltazar, Didactic proposal to include nanoscience and nanotechnology at high school curriculum linking physics, chemistry and biology, J. Phys. Conf. Series 1043, 012050 (2018).

[18] M. De Coce, Representation use, and strategy choice in physics problem solving, Phys. Rev. ST Phys. Educ. Res. 8, 2 (2012).

[19] C. Angel, P. M. Kind, E. K. Henriksen, and Ø. Guttersrud, An empirical-mathematical modeling approach to upper secondary physics, Phys. Educ. 43, 256 (2008).

[20] S. Abramovich, Conceptualizing energy by practicing scientists, in the online media and by junior high school students, thesis, Weizmann institute of science, 2019.

[21] Y. Feldman-Maggor, I. Tuvi-Arad, and R. Blonder, Online nanotechnology courses for teachers: Learning evaluation and learning patterns, in e-Proceeding at ESERA 2019, Bologna, Italy (2019).

[22] R. Blonder and E. Yonai, Exposing high-school students to nanoscience, in $21^{\text {st }}$ Century Nanoscience-A Handbook, edited by K. Sattler (CRC Press, Boca Raton, 2019), Chap. 9.

[23] R. Blonder, The influence of a teaching model in nanotechnology on chemistry teachers' knowledge and their teaching attitudes, J. Nano Educ. 2, 67 (2010). 